\title{
Electronic Voice for Set of the Syllables from Braille Code Input based on Microcontroller
}

Hidayat* and Anton Prafanto

\author{
Departement of Computer Engineering, University of Komputer Indonesia, Dipati Ukur No. 112-118, \\ Bandung - 40132,Indonesia; hidayat@email.unikom.ac.id, anton_prafanto@yahoo.com
}

\begin{abstract}
Objectives: This paper presents the design and implementation of an electronic device that can convert the input code be the voice corresponding braille code input. Methods/Statistical Analysis: This electronic device has some push button that used to enter the braille code. The microcontroller will read and convert them into character. This character will be displayed on the LCD monitor to ensure the correct or not. Microcontroller also function to set MP3 Player Module to run MP3 document that correspond the characters entered. All MP3 sound documents are stored on the SD card. Findings: This electronic device has the ability to recognize each character is entered in braille code via push button. Also, these electronic devices can recognize the arrangement of the characters that form syllables. Each character or syllable that has been entered can be voiced by this device. Arrangement of syllables that make up the word can also be voiced by device per syllable. Voicing any character and syllables using Indonesian. Application/Improvements: These electronic devices can be a media for learning to children with visual impairment or blind people to recognize braille code and how to pronounce it independently.
\end{abstract}

Keywords: Blind People, Braille Code, Electronic Voice, Microcontroller, Set of the Syllables

\section{Introduction}

This study discusses one effort to improve learning ability for blind people children in the face of challenges in the global era. According World Health Organization (WHO) said that 285 million people are estimated to be visually impaired (39 million are blind and 246 have low vision) and among $90 \%$ people live in countries with lowincome ${ }^{1}$. Limited ability to look for blind people children do not discourage them to get an education. So far, the government has efforts a special school for the blind people that Extraordinary School (SLB) A even though the amount is very limited. However, facilities and teaching aids for blind people are still conventional. Availability of electronic devices that can help blind people to be able to learn independently is very limited, so it is difficult for blind people to learn independently.

Application of ICT today, has supported to produce innovative devices that can help the visually impaired in learning activities ${ }^{2}$. Some research by Researchers have developed to facilitate learning tool for blind people or the visually impaired, for example, Refreshable Braille Display Controller $\underline{3}$, A Self-Learning Braille System for Visually Impaired ${ }^{4}$, FPGA based Braille to Text \& Speech for Blind Persons ${ }^{\underline{5}}$, and User Friendly System for the Visually Impaired in Learning Al-Quran ${ }^{6}$. The above problems, encourage researchers to design an electronic device voice for set of the syllables in Indonesian. The device is expected to help blind people children to recognize the arrangement of letters that form syllable independently.

\subsection{Braille Code}

Braille code is a writing touch system that is used by blind people. This system was originally designed by Louis Braille. Louis Braille was not able to see since childhood. At the age of 15 years, Louis Braille has successfully trans-

${ }^{*}$ Author for correspondence 
formed the ordinary into the Latin alphabet letters touch that can be read by blind people as well as normal people in the dark ${ }^{7}$. The arrangement of dots that form the Braille characters in Braille code is shown on Figure 1. And the braille code for characters from ' $a$ ' to ' $z$ ' character that used in the system is shown in Figure 2.

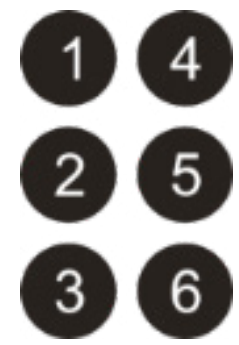

Figure 1. The dots arrangement of braille code.

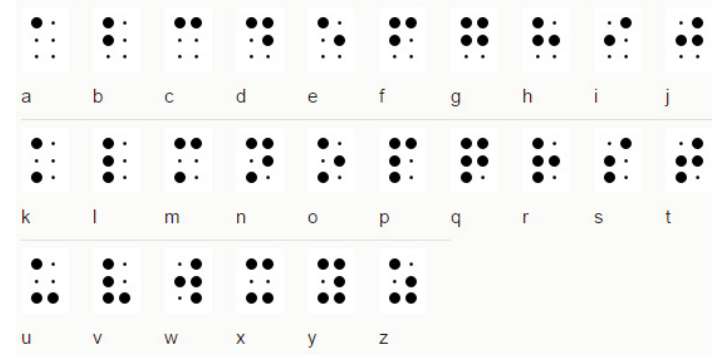

Figure 2. Braille code for alphabet ${ }^{\underline{T}}$.

\subsection{Keys of Braille Typewriter}

Braille typewriter has only six keys. Each of these keys will generate the dots on braille code. Each of these keys has a number corresponding to the position of the braille code ${ }^{8}$. Arrangement of keys on a Braille typewriter arranged from left to right in order of the number dots $3,2,1,4,5,6$. The arrangement of keys on a braille typewriter shown in Figure 3. The arrangement of keys on a Braille typewriter became standard input data used in the design of electronic devices voice for syllables.

\section{Design}

This design consist of hardware design, software design and mechanic design.

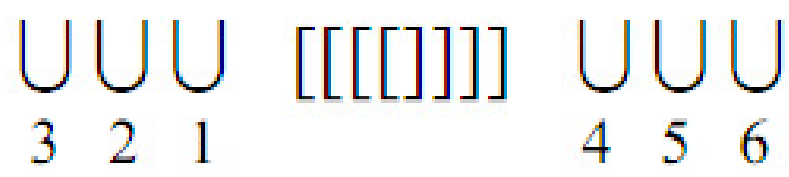

Figure 3. Keys arrangement of Braille typewriter $\stackrel{\text {. }}{ }$

\subsection{Hardware Design}

Hardware design is done to determine the components that will be used in electronic devices voice for syllables. The overall system design of electronic devices voice for syllables is shown in Figure 4.

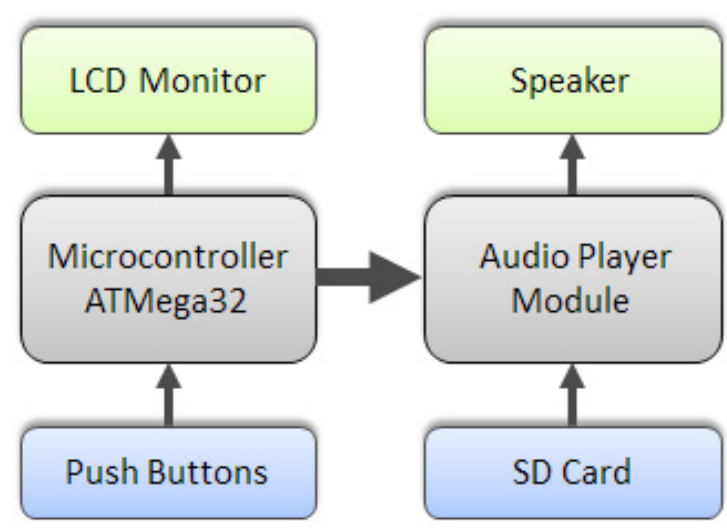

Figure 4. System block diagram.

The sections on the block diagram above are described below

- Push-buttons section: Contains nine pushbutton. Six push-buttons are arranged adjusting arrangement of keys on a braille typewriter for enter braille code. One push-button is used to cancel the braille code data that has been entered. One push-button is used to validate braille code to be entered. One push-button is used to process the arrangement of the braille code has been entered. Push-button arrangement is shown in Figure 5.

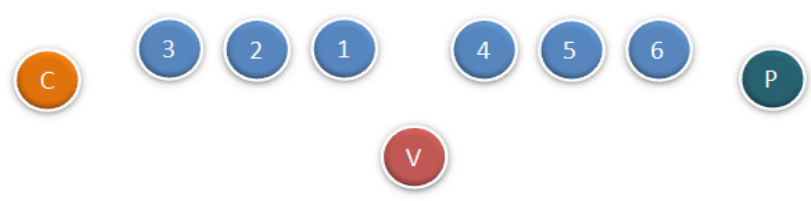

Figure 5. Arrangement of push-buttons.

- Microcontroller section: Contains ATMega32. This microcontroller uses RISC architecture which has 131 instructions. Most instructions can be executed in one clock cycle 9 . In this scheme, ATMega32 is used for the conversion process code braille to-case characters, the processing of data to be displayed on the LCD monitor and the setting on the document mp3 to be executed by the module MP3 DF Player Mini DFR0299. The 
configuration of the pins on the microcontroller used in the design is shown Table 1.

Table 1. Pins Configuration of Microcontroller

\begin{tabular}{|l|l|l|l|}
\hline PIN & No.Pin & I/O & Function \\
\hline PA0 & 40 & I & Push Button1 \\
\hline PA1 & 39 & I & Push Button2 \\
\hline PA2 & 38 & I & Push Button3 \\
\hline PA3 & 37 & I & Push Button4 \\
\hline PA4 & 36 & I & Push Button5 \\
\hline PA5 & 35 & I & Push Button6 \\
\hline PB0 & 1 & O & Bit 4 LCD \\
\hline PB1 & 2 & O & Bit 5 LCD \\
\hline PB2 & 3 & O & Bit 6 LCD \\
\hline PB3 & 4 & O & Bit 7 LCD \\
\hline PC1 & 23 & I & Play Button \\
\hline PC2 & 24 & I & Clear Button \\
\hline PC7 & 29 & I & Validation Button \\
\hline PD0 & 14 & I & Rx \\
\hline PD1 & 15 & O & Tx \\
\hline PD2 & 16 & O & En \\
\hline PD3 & 17 & I & Buzy \\
\hline PD4 & 18 & O & Buzzer \\
\hline PD6 & 20 & O & RS LCD \\
\hline PD7 & 21 & O & E LCD \\
\hline
\end{tabular}

- LCD Monitor section: Includes 16 × 2 LCD monitor that has the ability to display 32 characters.

- This LCD monitor use to display information conversion result of the input data in the form of braille code in the form of characters.

- Audio Player Module section: Contains MP3 Player Mini DFR0299. DFR0299 module has the ability to decode WMV and MP3 sound document $t^{10}$. This module will run $\mathrm{mp} 3$ document based on commands from the microcontroller. The MP3 module components used in the design is shown in Figure 6.

- MicroSD section: Contains Secure Digital (SD) card already contains MP3 document. SD card is a non-volatile memory card format developed by the SD Card Association (SDA) for use in portable devices ${ }^{11}$. Sound set of documents to be executed by the Mini MP3 DFPlayer DFR0299 module to read a syllable that has been entered by the user.

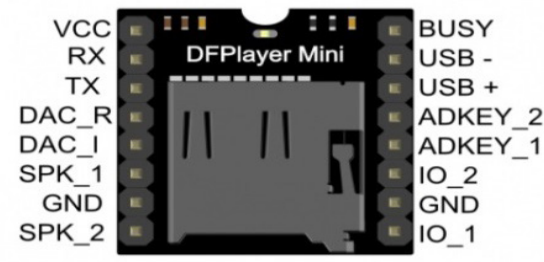

Figure 6. MP3 DFR0299 module ${ }^{6}$.

- Speaker section: Contains a device that produces sound from mp3 document resulting from MP3 DFPlayer DFR0299 Module.

\subsection{Software Design}

Software design consists of several stages, namely the determination of syllables that can be read by the system, the manufacture of MP3 documents, the determination of the input code, the production of flow charts and the implementation of program using microcontroller.

\subsection{The Determination of Syllables}

In this stage, the determination of syllables that can be read by the system. Syllables are formed from the combination Vocals (V) and consonant characters (K). Furthermore, the grouping of all the syllables that can be read by the system based on the initial characters. Here is the pattern of syllables-syllables that can be read by the system, including:

- V consists of 5 pieces; VK consists of 41 pieces;

- VKK consists of 5 pieces; $K$ consists of 21 pieces;

- KV consists of 109 pieces; KVK consists of 648 pieces;

- KVKK consists of 78 pieces; KKV consists of 10 pieces;

- KKVK consists of 8 pieces.

\subsection{The Manufacture of MP3 Document}

At this stage, each syllable sound recording that is readable by the system. Each syllable will be emitted in one document mp3. All MP3 documents are stored in the SD card.

\subsection{The Determination of the Input Code}

In this stage, the determination of the character input code is based on combination of push button. The combination 
of push button and decimal code on the microcontroller to determine a specific character are shown in Table 2 .

Table 2. The letter, a combination push button and decimal code

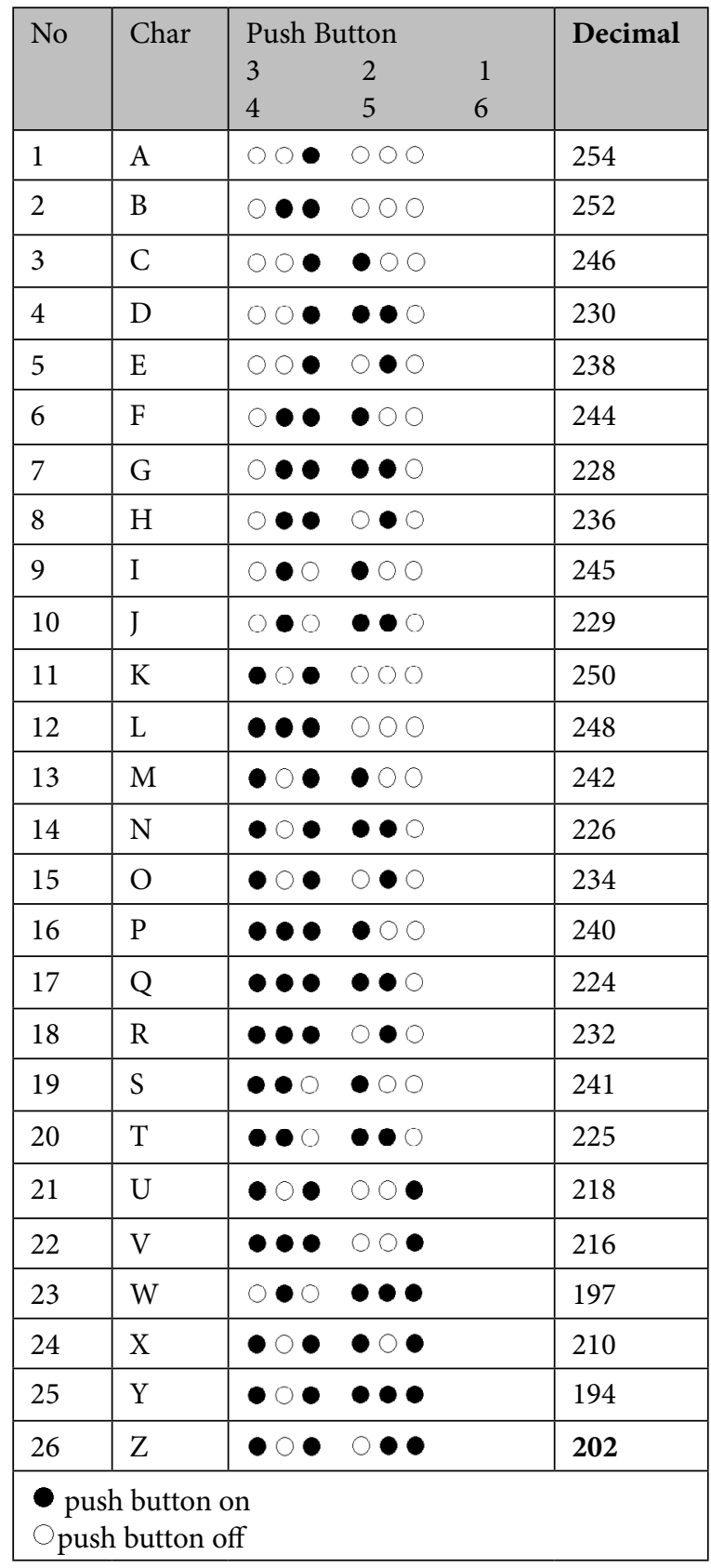

\subsection{The Production of Flow Charts}

In this stage, the determination of program flow diagram that will be embedded in the microcontroller. The main program flow diagram on a microcontroller as the main controller is shown in Figure 7.

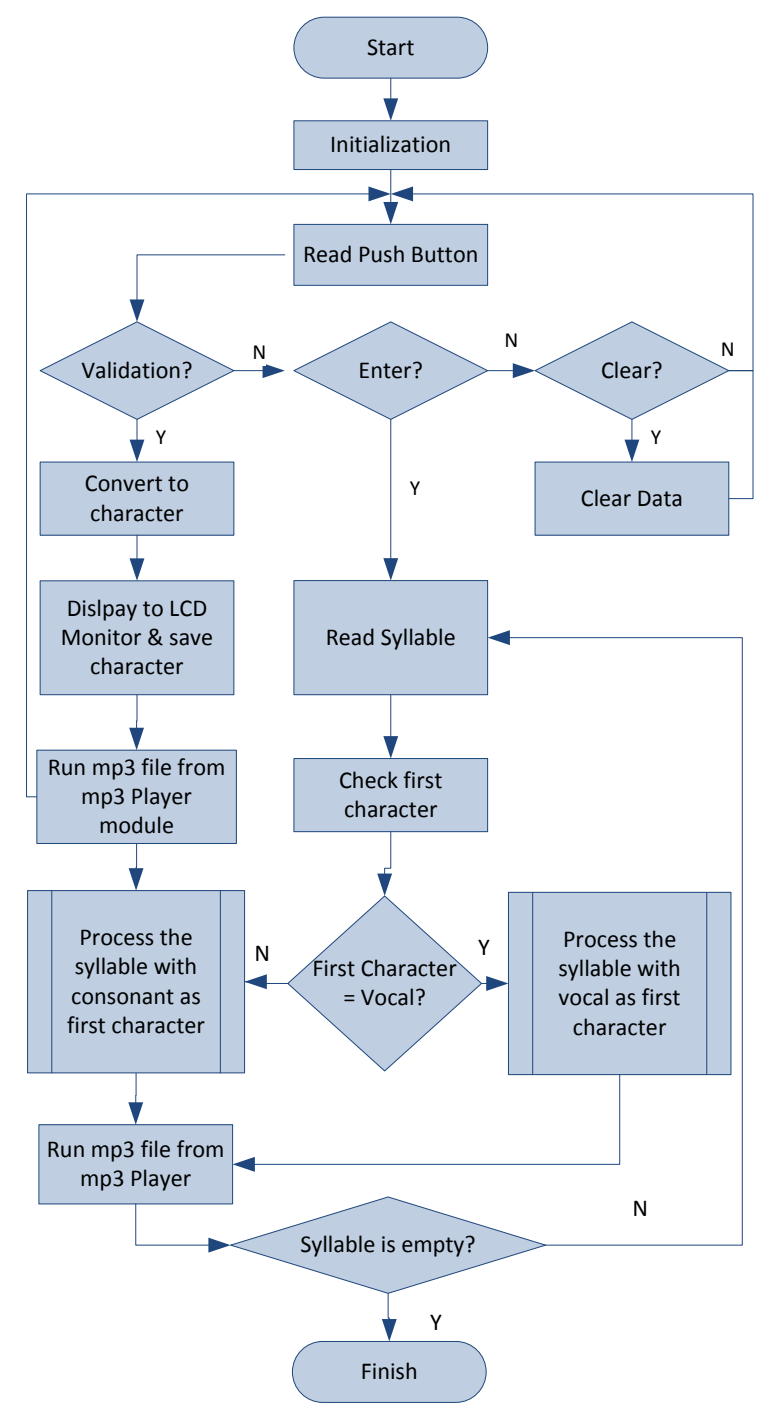

Figure 7. The main program flow diagram.

Description main flow chart is described in the following section.

- Initialization is the beginning of the program to determine the variables and ports used in the system.

- The next process, the system will read any input from the push button.

- Furthermore, the system will read one of the three push button that serves as the validation of the character, the Enter key to start the reading of syllables and the Clear button to delete the data.

- If the validation button is pressed, the system will convert the input code into Braille characters, displays it on the LCD monitor, store these characters in memory and execute the appropri- 
ate documents $\mathrm{mp} 3$ characters resulting from the conversion process. Furthermore, the system will return to the process of reading push button.

- If the Clear button is pressed, the system will erase all data previously entered characters ever and back to the beginning of the reading push button.

- If the Enter button is pressed, the system will start reading the beginning of syllables and check the character, whether syllable entered initiated by vowel or consonant characters. Furthermore, the system will process the corresponding initial conditions characters. If the beginning of the character of the vocals, the process of determining syllables done on the syllable proceeded by a vowel character. If the beginning of the character of the process of determining the character consonant syllables done on the syllable proceeded by a consonant characters.

- Next, the system will run mp3 document that corresponds to predefined syllable in the previous process.

- If a user enters a few letters that form word, the system will repeat to read per syllable.

- Last, if the syllable is empty, the system will finish to read syllable.

\subsection{Program Implementation}

In this stage, the implementation of the flow diagram in the form of programs that can be embedded in the microcontroller.

\section{Result and Discussion}

Prototype of electronic device is shown in Figure 8. This device uses a battery power supply so that the portable to carry around.

The test is performed to determine whether the tool or system is functioning correctly or not. This test consists of testing the input, testing syllable sound output from MP3 DFPlayer module controlled by the microcontroller.

\subsection{Testing of Data Input}

In this test, testing input characters from the character ' $a$ ' to the character ' $\mathrm{z}$ '. Input entered form of the composition buttons that form the braille code. The test results are shown in Table 3. It shows that all the characters needed on this device both vowels and consonants have been functioning properly.

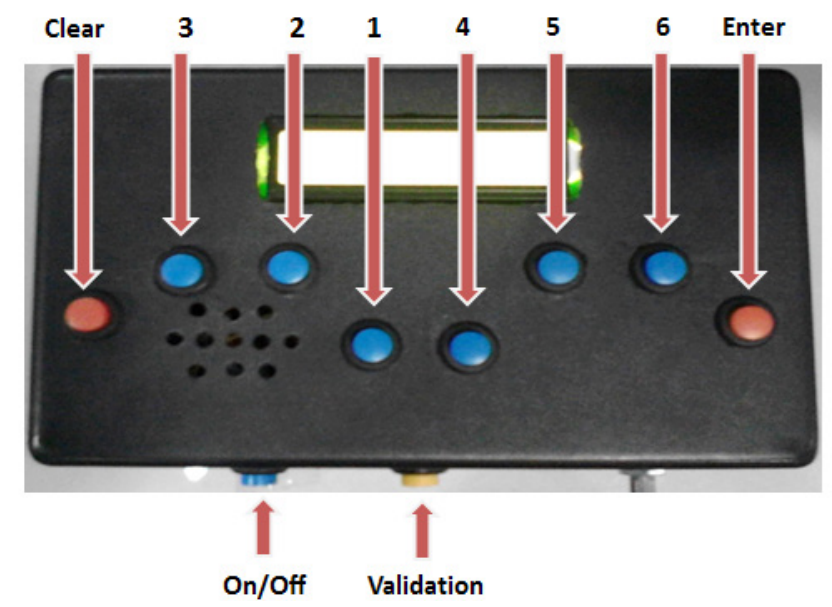

Figure 8. Electronic devices syllable pronunciation.

Table 3. The test results of data input

\begin{tabular}{|c|c|c|c|}
\hline No & Push Button & LCD & Validation \\
\hline & $\begin{array}{lllll}2 & 1 & 4 & 5 & 6\end{array}$ & & \\
\hline 1 & $00 \bullet 000$ & A & Ö \\
\hline 2 & $0 \bullet 000$ & B & Ö \\
\hline 3 & $00 \bullet \bullet 00$ & $\mathrm{C}$ & Ö \\
\hline 4 & $00 \bullet \bullet \bullet 0$ & $\mathrm{D}$ & Ö \\
\hline 5 & $00 \bullet 0 \bullet 0$ & E & Ö \\
\hline 6 & $0 \bullet \bullet 00$ & $\mathrm{~F}$ & Ö \\
\hline 7 & $0 \bullet \bullet \bullet \bullet 0$ & G & Ö \\
\hline 8 & $0 \bullet \bullet \quad \bullet$ & $\mathrm{H}$ & Ö \\
\hline 9 & $0 \bullet 000$ & I & Ö \\
\hline 10 & $0 \bullet 0 \bullet 0$ & $\mathrm{~J}$ & Ö \\
\hline 11 & 00000 & $\mathrm{~K}$ & Ö \\
\hline 12 & $\bullet \bullet \bullet 000$ & $\mathrm{~L}$ & Ö \\
\hline 13 & $-\circ \bullet 00$ & $\mathrm{M}$ & Ö \\
\hline 14 & $\bullet \circ \bullet \bullet 0$ & $\mathrm{~N}$ & $\ddot{\mathrm{O}}$ \\
\hline 15 & $\bullet \circ \bullet \circ \bullet$ & $\mathrm{O}$ & Ö \\
\hline 16 & $\bullet \bullet \bullet \bullet \circ 0$ & $\mathrm{P}$ & Ö \\
\hline 17 & $\bullet \bullet \bullet \bullet \bullet$ & Q & Ö \\
\hline 18 & $\bullet \bullet \bullet \quad \bullet$ & $\mathrm{R}$ & Ö \\
\hline 19 & $\bullet \bullet 0 \bullet 00$ & $S$ & Ö \\
\hline 20 & $\bullet \bullet \bullet \bullet \bullet$ & $\mathrm{T}$ & Ö \\
\hline 21 & $\bullet \circ \bullet$ & U & Ö \\
\hline
\end{tabular}




\begin{tabular}{|c|c|c|c|}
\hline 22 & $\bullet \bullet \bullet \quad 00 \bullet$ & $\mathrm{V}$ & Ö \\
\hline 23 & 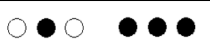 & $\mathrm{W}$ & Ö \\
\hline 24 & $\bullet \circ \bullet \bullet$ & $\mathrm{X}$ & Ö \\
\hline 25 & $\bullet \bullet \bullet \bullet \bullet$ & $\mathrm{Y}$ & Ö \\
\hline 26 & $\bullet \circ \bullet$ & $\mathrm{Z}$ & Ö \\
\hline
\end{tabular}

\subsection{Testing of Syllable from Two Letters}

In this test done by inserting a few syllables composed of two characters. The test results syllable consisting of two letters are shown in Table 4 . It shows that the device can recognize syllables consisting of two letters correctly.

Table 4. The test results are two-letter syllable

\begin{tabular}{|c|c|c|c|}
\hline No. & Data Input & LCD & Validation \\
\hline 1 & $\mathrm{AB}$ & $\mathrm{AB}$ & $\sqrt{ }$ \\
\hline 2 & $\mathrm{AD}$ & $\mathrm{AD}$ & $\sqrt{ }$ \\
\hline 3 & $\mathrm{AF}$ & $\mathrm{AF}$ & $\sqrt{ }$ \\
\hline 4 & $\mathrm{AG}$ & $\mathrm{AG}$ & $\sqrt{ }$ \\
\hline 5 & $\mathrm{AH}$ & $\mathrm{AH}$ & $\sqrt{ }$ \\
\hline 6 & $\mathrm{AK}$ & $\mathrm{AK}$ & $\sqrt{ }$ \\
\hline 7 & $\mathrm{AL}$ & $\mathrm{AL}$ & $\sqrt{ }$ \\
\hline 8 & $\mathrm{AM}$ & $\mathrm{AM}$ & $\sqrt{ }$ \\
\hline 9 & AN & $\mathrm{AN}$ & $\sqrt{ }$ \\
\hline 10 & $\mathrm{AP}$ & $\mathrm{AP}$ & $\sqrt{ }$ \\
\hline 11 & $\mathrm{AR}$ & $\mathrm{AR}$ & $\sqrt{ }$ \\
\hline 12 & AS & AS & $\sqrt{ }$ \\
\hline 13 & $\mathrm{AT}$ & $\mathrm{AT}$ & $\sqrt{ }$ \\
\hline 14 & AV & $\mathrm{AV}$ & $\sqrt{ }$ \\
\hline 15 & IG & IB & $\sqrt{ }$ \\
\hline 16 & $\mathrm{IH}$ & $\mathrm{IH}$ & $\sqrt{ }$ \\
\hline 17 & IJ & IJ & $\sqrt{ }$ \\
\hline 18 & IK & IK & $\sqrt{ }$ \\
\hline 19 & $\mathrm{IM}$ & IM & $\sqrt{ }$ \\
\hline 20 & IN & IN & $\sqrt{ }$ \\
\hline
\end{tabular}

\subsection{Testing of Syllable from Three Letters}

In this test done by inserting several syllables consisting of three letters. The test results syllables comprised of three letters are shown in Table 5. It indicates that the device can recognize syllables consisting of three letters properly.
Table 5. The test results are three-letter syllable

\begin{tabular}{|l|l|l|l|}
\hline No. & Data Input & LCD & Validation \\
\hline 1 & BAB & BAB & $\sqrt{ }$ \\
\hline 2 & BAD & BAD & $\sqrt{ }$ \\
\hline 3 & BIH & BIH & $\sqrt{ }$ \\
\hline 4 & BUH & BUH & $\sqrt{ }$ \\
\hline 5 & BAM & BAM & $\sqrt{ }$ \\
\hline 6 & BIM & BIM & $\sqrt{ }$ \\
\hline 7 & BUM & BUM & $\sqrt{ }$ \\
\hline 8 & BEM & BEM & $\sqrt{ }$ \\
\hline 9 & BOM & BOM & $\sqrt{ }$ \\
\hline 10 & BAN & BAN & $\sqrt{ }$ \\
\hline 11 & BIN & BIN & $\sqrt{ }$ \\
\hline 12 & BUN & BUN & $\sqrt{ }$ \\
\hline 13 & BEN & BEN & $\sqrt{ }$ \\
\hline 14 & BON & BON & $\sqrt{ }$ \\
\hline 15 & BAP & BAP & $\sqrt{ }$ \\
\hline 16 & BAR & BAR & $\sqrt{ }$ \\
\hline 17 & BIR & BIR & $\sqrt{ }$ \\
\hline 18 & BUR & BUR & $\sqrt{ }$ \\
\hline 19 & BER & BER & $\sqrt{ }$ \\
\hline 20 & BOR & BOR & $\sqrt{ }$ \\
\hline
\end{tabular}

\subsection{Testing of Syllable from Four Letters}

In this test done by inserting several syllables composed of four letters. The test results syllable of four letters are shown in Table 6. It shows that the device able to identify syllables consisting of four letters correctly.

Table 6. The test results of four-letter syllable

\begin{tabular}{|l|l|l|l|}
\hline No. & Data Input & LCD & Validation \\
\hline 1 & BANG & BANG & $\sqrt{ }$ \\
\hline 2 & BING & BING & $\sqrt{ }$ \\
\hline 3 & BUNG & BUNG & $\sqrt{ }$ \\
\hline 4 & BENG & BENG & $\sqrt{ }$ \\
\hline 5 & BONG & BONG & $\sqrt{ }$ \\
\hline 6 & CANG & CANG & $\sqrt{ }$ \\
\hline 7 & CING & CING & $\sqrt{ }$ \\
\hline 8 & CUNG & CUNG & $\sqrt{ }$ \\
\hline 9 & CENG & CENG & $\sqrt{ }$ \\
\hline 10 & CONG & CONG & $\sqrt{ }$ \\
\hline 11 & DANG & DANG & $\sqrt{ }$ \\
\hline 12 & DING & DING & $\sqrt{ }$ \\
\hline
\end{tabular}




\begin{tabular}{|l|l|l|l|}
\hline 13 & DUNG & DUNG & $\sqrt{ }$ \\
\hline 14 & DENG & DENG & $\sqrt{ }$ \\
\hline 15 & NGAH & NGAH & $\sqrt{ }$ \\
\hline 16 & NGAN & NGAN & $\sqrt{ }$ \\
\hline 17 & NGAT & NGAT & $\sqrt{ }$ \\
\hline 18 & NYAH & NYAH & $\sqrt{ }$ \\
\hline 19 & NYAK & NYAK & $\sqrt{ }$ \\
\hline 20 & NYAL & NYAL & $\sqrt{ }$ \\
\hline
\end{tabular}

\subsection{Testing set of Syllable}

In this test done by inserting several set of syllables that form word. The test results are shown in Table 7. It shows that the device able to identify set of syllables correctly.

Table 7. The test results of four-letter syllable

\begin{tabular}{|l|l|l|l|}
\hline No. & Data Input & LCD & Validation \\
\hline 1 & ABADI & ABADI & $\sqrt{ }$ \\
\hline 2 & BUKU & BUKU & $\sqrt{ }$ \\
\hline 3 & CENDEKIA & CENDEKIA & $\sqrt{ }$ \\
\hline 4 & DARURAT & DARURAT & $\sqrt{ }$ \\
\hline 5 & EKONOMI & EKONOMI & $\sqrt{ }$ \\
\hline 6 & GANGGUAN & GANGGUAN & $\sqrt{ }$ \\
\hline 7 & HINGGA & HINGGA & $\sqrt{ }$ \\
\hline 8 & INGATAN & INGATAN & $\sqrt{ }$ \\
\hline 9 & JERAPAH & JERAPAH & $\sqrt{ }$ \\
\hline 10 & KANGGURU & KANGGURU & $\sqrt{ }$ \\
\hline 11 & LUMAYAN & LUMAYAN & $\sqrt{ }$ \\
\hline 12 & MANGGA & MANGGA & $\sqrt{ }$ \\
\hline 13 & NYATA & NYATA & $\sqrt{ }$ \\
\hline 14 & BERHASIL & BERHASIL & $\sqrt{ }$ \\
\hline 15 & SEMANGAT & SEMANGAT & $\sqrt{ }$ \\
\hline 16 & REFORMASI & REFORMASI & $\sqrt{ }$ \\
\hline 17 & SEMANGAT & SEMANGAT & $\sqrt{ }$ \\
\hline 18 & NYATA & NYATA & $\sqrt{ }$ \\
\hline 19 & NYANYIAN & NYANYIAN & $\sqrt{ }$ \\
\hline 20 & SELESAI & SELESAI & $\sqrt{ }$ \\
\hline
\end{tabular}

\section{Conclusion}

The results of the design and testing of an electronic device syllable pronunciation indicates that the device is already work well. This is shown by the following capabilities:

- Each input braille code which comes from the push button that is pressed can be converted into

characters and displayed on the LCD and read by the system in accordance with mp3 documents that have been saved.

- The device can recognize and read the letters that form syllables that have been enrolled on the system, consisting of two letters, three letters or four letters.

- The device can recognize and read several syllables those form words that have been listed on the system.

Further research is adding the ability to be able to recognize text that is composed of several word.

\section{Acknowledgment}

We said thanks to the Directorate General of Research and Development KEMENRISTEKDIKTI of Republic of Indonesia, which had funded research activities in the competitive grants research schemes in 2015 and 2016, and we said thanks to the University Computer Indonesia, which has facilitated the research activities at the Laboratory of Digital Systems, and also, we said thanks to students with visual impairment in ordinary school of Wyata Guna Bandung.

\section{References}

1. Visual impairment and blindness. [internet]. 2015. Available from: http://www.who.int/mediacentre/factsheets/fs282/en/

2. ICT as a Tool for Teaching and Learning in Respect of Learner with Disability [internet]. 2015. Available from: http://wikieducator.org/images/7/7b/SJ_M.P.Mishra.pdf

3. Gupta R, Singh PK, Bhanot S. Design and Implementation of Arduino based Refreshable Braille Display Controller. Indian Journal of Science and Technology. 2016 Sept; 9(33):1-5.

4. Khidri SA, Memon SH, Jameel A. Blind Aid: A self-learning Braille system for visually impaired. International Journal of Engineering Research and General. 2014 Jun-Jul; 4(2):641-7.

5. Rajarapollu P, Kodolikar S, Laghate D, Khavale A. FPGA based Braille to text and speech for blind persons. International Journal of Scientific and Engineering Research. 2013 Apr; 4(4):348-53.

6. Razaly F, Ajizan NH, Saad SM, Yaacob MS, Zain MZ, Hussein M, Abdullah MY, Musa AR. User friendly system for the visually impaired in learning Al-Quran. WSEAS Transactions on Systems. 2010 Jun; 9(6):659-68. 
7. Louis Braille and the Braille System [internet]. 2015. Available from: http://www.duxburysystems.com/braille. asp

8. Risjord C. Instruction manual for Braille transcribing. Library of Congress. 2009.

9. Atmel 8-Bit Microcontroller with 4/8/16/32kbytes in-System Programmable Flash [internet]. 2015. Available from: http://www.atmel.com/images/Atmel-8271-8-bit-AVR-
Microcontroller-ATmega48A-48PA-88A-88PA-168A168PA-328-328P_datasheet_Complete.pdf.

10. DFPlayer - A Mini MP3 Player [internet]. 2014. Available form: http://www.dfrobot.com/image/data/DFR0299/ DFPlayer\%20Mini\%20Manual.pdf.

11. Secure Digital [Internet]. 2015. Available form: https:// en.wikipedia.org/wiki/Secure_Digital 